\title{
Detection of Inducible Clindamycin Resistance Genes (ermA, ermB, and ermC) in Staphylococcus aureus and Staphylococcus epidermidis
}

\author{
Mohammad Javad Mazloumi ${ }^{1}$, Reza Akbari ${ }^{1}$, and Saber Yousefi ${ }^{1,2 *}$ \\ ${ }^{1}$ Department of Microbiology and Virology, Faculty of Medicine, ${ }^{2}$ Cellular and Molecular Research Center, Faculty of Medicine, \\ Urmia University of Medical Sciences, Urmia 57157-99313, Iran
}

Received: March 25, 2021 / Revised: July 17, 2021 / Accepted: July 21, 2021

\begin{abstract}
The aim of the present study was to survey the frequency of inducible and constitutive phenotypes and inducible cross-resistant genes by regulating the methylation of $23 \mathrm{~S}$ rRNA (ermA, ermB, and ermC) and macrolide efflux-related $m s r A$ gene in Staphylococcus aureus and S. epidermidis strains. A total of 172 bacterial isolates (identified based on standard tests), were examined in this study. Antibiotic susceptibility was determined by the disk diffusion method, and all isolates were evaluated with respect to inducible and constitutive phenotypes. The presence of erm $A$, ermB, erm $C$, and $m s r A$ genes was investigated by a PCR assay. The constitutive resistance phenotypes showed a higher distribution among the isolates. $R$ phenotype was detected more among $S$. epidermidis isolates (46.25\%). ermB, ermC, and msrA genes were detected more in methicillin-resistant S. aureus (MRSA) and methicillin-resistant S. epidermidis (MRSE) isolates that had $\mathrm{R}$ and HD phenotypes ( $>77 \%$ strains). The ermA gene had the lowest frequency among MRSA, MRSE, MSSA, and MSSE strains ( $<14 \%$ isolates). Distribution of inducible resistance genes in MRSA and MRSE strains, and possibly other species, leads to increased constitutive resistance to erythromycin, clindamycin, and other similar antibiotics. Therefore, it can be challenging to treat infections caused by these resistant strains.
\end{abstract}

Keywords: D-phenotypes, inducible resistance, constitutive resistance, Staphylococcus aureus, Staphylococcus epidermidis

\section{Introduction}

Staphylococcus aureus is an important pathogen with a significant infectious potential due to its high pathogenicity and involvement in a broad range of infections. The advent of multidrug resistance in S. aureus is one of the most important challenges in health settings worldwide [1]. Macrolides, such as erythromycin, constitute an antibiotic group against infections caused by $S$. aureus and Staphylococcus epidermidis. As a result of their expanded use, resistance to erythromycin and other

\section{*Corresponding author}

Tel.: +98 4432770698 Ext. 213, Fax: +98 4432780800

E-mail:yousefi_s@umsu.ac.ir macrolides has increased in S. aureus and S. epidermidis strains. Generally, several mechanisms are involved in macrolide resistance of $S$. aureus isolates. The most well-known mechanism in resistance to erythromycin is the reduced affinity of antibiotics for ribosomes due to ribosomal binding site modifications [2].

Clindamycin is used in the treatment of $S$. aureus infections. It is an effective drug for infections caused by $S$. aureus in case of resistance to beta-lactam antibiotics. Clindamycin and erythromycin exhibit good antibacterial activities against infections. In addition, clindamycin shows potential activity against communityacquired methicillin-resistant $S$. aureus. These strains are the most prevalent pathogens in the community [2]. Studies show that resistance to clindamycin in $S$. aureus 
and S. epidermidis strains is increasing worldwide.

Staphylococci acquire resistance to macrolides and also clindamycin by two primarymechanisms: macrolide efflux encoded by msrA gene and modification of drug binding site on ribosome controlled by erythromycin resistance methylase ( $\mathrm{rm}$ ) genes. Methylases reduce binding of erythromycin or in overall $\mathrm{MLS}_{\mathrm{B}}{ }^{1}$ antibiotics to the target site in the $50 \mathrm{~S}$ ribosomal subunit. ermA, erm $B$ and erm $C$ are three common genes responsible for the erythromycin resistance in $S$. aureus. The msrA gene is an ATP binding cassette transporter in the cell wall of the bacteria that induce resistance in staphylococci by extruding antibiotics to the outside of the cell [3]. The efflux mechanism yields inducible resistance to macrolides (azithromycin, erythromycin, clarithromycin, and roxithromycin) and also type B streptogramins, while it is not active against lincosamides (clindamycin and lincomycin). Inducible resistant includes two kinds of phenotypes; $\mathrm{D}$ and $\mathrm{D}^{+}$. In $\mathrm{D}$ phenotype, the bacteria are resistant to erythromycin and a D-shaped clear zone is formed around the clindamycin disk proximal to the erythromycin disk. In the $\mathrm{D}^{+}$phenotype, in addition to the D-shaped zone around the clindamycin disk, small colonies are seen at the inhibition zone of the clindamycin disk.Ribosomal methylation causes cross-resistance to macrolides, lincosamides, and type B streptogramins. In Staphylococci, erm $\mathrm{A}$, remB, or erm $\mathrm{C}$ genes are responsible for the cross-resistant phenotype by regulation the methylation of $23 \mathrm{~S}$ rRNA binding region. Methylation process reduces the affinity of macrolides, lincosamides, and type B streptogramins that share the common binding site. Constitutive resistant includes two kinds of phenotypes; HD (hazy D zone) and R (Resistant). In HD phenotype, in addition to the observed bacterial growth at the presence of erythromycin, two zones of growth could be observed around the clindamycin disk. In $\mathrm{R}$ phenotype, bacterial colonies are seen in the presence of erythromycin and clindamycin. S (Sensitive) phenotype and Neg (negative) phenotype also can be considered to erythromycin and clindamycin other than inducible and constitutive phenotypes. In $\mathrm{S}$ phenotype, the bacteria growth is not seen in the presence of erythromycin and clindamycin. In Neg phenotype, the bacteria is resistant to erythromycin while D shaped

1. Macrolide, lincosamide and streptogramin type B clear zone is not seen around the clindamycin disk proximal to the erythromycin disk [4].

S. epidermidis is most frequently isolated from clinical cultures, especially urine and blood with the use of catheters. S. epidermidis accounts for approximately $13 \%$ of all cases of prosthetic valve endocarditis and $38 \%$ of all cases of cardiac abscess formation. It is also associated with a mortality rate of $24 \%$ [5]. Similar to $S$. aureus, $S$. epidermidis resistance to macrolides is mediated by methylases encoded by erm genes (modifying the ribosomal target of macrolides) or efflux pumps encoded by $m s r A$ genes [6].

D-zone test, a disk test incorporating erythromycin and clindamycin disks, is defined by the Clinical and Laboratory Standards Institute (CLSI, 2017) [7]. This test represents the inducible resistance of Staphylococci. With this background in mind, in the present study, we aimed to investigate the frequency of clindamycin inducible resistance genes (ermA, ermB, and erm C) in $S$. aureus and $S$. epidermidis strains isolated from various clinical samples.

\section{Materials and Methods}

\section{Bacterial strains}

All Gram-positive cocci, suspected to belong to the genus Staphylococcus were collected from Imam Hospitals of Urmia and Naqadeh in West Azerbaijan from October 2014 to October 2017. All bacterial isolates were identified by using microbiological protocols. For this purpose, samples were cultivated on nutrient agar at $37^{\circ} \mathrm{C}$ for $24 \mathrm{~h}$. Primary single colonies were subcultured on blood agar plates to obtain pure cultures. The isolated colonies were stored in skim milk (Biomark, India), enriched with glycerol $16 \%$ at $-20^{\circ} \mathrm{C}$ for further use. Macroscopic and microscopic characteristics were studied using mannitol salt agar, blood agar, and biochemical tests with coagulase and catalase as standard protocols. In addition, all bacterial isolates were confirmed by amplification of $16 \mathrm{~S}$ rRNA gene using PCR method. The reference strains of $S$. aureus ATCC 25923 and S. epidermidis ATCC 12228 were used as the controls [8, 9].

\section{Antibiotic susceptibility testing}

Antibiotic susceptibility of the isolates was analyzed based on the CLSI guidelines [7]. The following antimi- 
crobial disks (Mast, UK) were used in this study: oxacillin, cefoxitin, tetracycline, clindamycin, rifampicin, erythromycin, linezolid, fusidic acid, gentamicin, and mupirocin. Bacterial suspensions were adjusted at $625 \mathrm{~nm}$ to obtain $1.5 \times 10^{8} \mathrm{CFU} / \mathrm{ml}$ as the reference $0.5 \mathrm{McF}$ arland standard. Optical density was set in the range of 0.08 0.13. Standard strains, including S. aureus ATCC 29213 and S. epidermidis ATCC 12228, were used as quality control for antimicrobial susceptibility testing.

\section{D-test}

Standard CLSI double-disk diffusion test (D test) was performed using Mueller-Hinton agar (Merck, Germany) with a $15-\mu \mathrm{g}$ erythromycin disk and a $2-\mu \mathrm{g}$ clindamycin disk (Merck), placed at a 15-mm distance and incubated for $24 \mathrm{~h}$ at $35^{\circ} \mathrm{C}$ [8]. Standard strains including S. aureus ATCC 29213 and S. epidermidis ATCC 12228 were used as quality control for antimicrobial susceptibility testing.

\section{Molecular techniques}

DNA of isolated bacteria was extracted by CinnaGen kit (Iran), as recommended by the manufacturer. The presence of erythromycin-resistant methylase genes, including erm $A$, ermB, and erm $C$, and also $m s r A$ gene was confirmed in isolates by PCR method. The antibiotic resistance gene primers were selected from previous studies [10], as shown in Table 1.

To perform PCR, $2 \mu$ l of each DNA dilution was transferred directly to a $25-\mu \mathrm{l} \mathrm{PCR}$ mixture, containing $23 \mu \mathrm{l}$ of Master Mix and $2 \mu \mathrm{l}$ of each primer (Bioneer Co.,
Korea). The PCR mixtures were subjected to thermal cycling in a thermocycler (Bioer Co., China). The protocol for ermA, ermB, and erm $C$ genes was as follows: denaturation for four minutes at $94^{\circ} \mathrm{C}$, followed by 35 cycles of denaturation at $94^{\circ} \mathrm{C}$ for $30 \mathrm{sec}$, annealing at $54^{\circ} \mathrm{C}$ for $60 \mathrm{sec}$, extension at $72^{\circ} \mathrm{C}$ for $45 \mathrm{sec}$, and final extension for seven minutes at $72^{\circ} \mathrm{C}$. This protocol was also used for the 16S rRNA gene. The annealing temperature for $16 \mathrm{~S}$ rRNA was $54^{\circ} \mathrm{C}$. The protocol for PCR of $m s r A$ gene was as follow: primary denaturation for five minutes at $94^{\circ} \mathrm{C}$, followed by 35 cycles of denaturation at $94^{\circ} \mathrm{C}$ for $60 \mathrm{sec}$, annealing at $52^{\circ} \mathrm{C}$ for $60 \mathrm{sec}$, extension at $72^{\circ} \mathrm{C}$ for $45 \mathrm{sec}$, and final extension for seven minutes at $72^{\circ} \mathrm{C}$.

\section{Results}

\section{Bacterial prevalence in clinical specimens}

Out of 172 isolates, $92(53.5 \%)$ and 80 (46.5\%) were identified as $S$. aureus and S. epidermidis, respectively. Distribution of positive clinical specimens for $S$. aureus was as follows: urine $(80.4 \%)$, blood $(7.6 \%)$, wound (6.5\%), sputum ( $2.2 \%)$, catheter $(0 \%)$, stretcher $(0 \%)$, and thermometer (1.1\%). S. aureus was isolated at a high rate from urine samples (80.4\%), whereas it was not detected in catheter or patient's bed samples $(0 \%)$. In addition, S. epidermidis was isolated from $77.5 \%$ of urine specimens, while it was not identified in thermometer or wound samples (0\%). Distribution of bacterial strains in the clinical specimens is shown in Table 2.

Table 1. Information for primers used in this study.

\begin{tabular}{|c|c|c|c|c|}
\hline Primer & Primer sequence $\left(5^{\prime}-3^{\prime}\right)$ & Product size (bp) & Annealing temperature & Reference \\
\hline 16S rRNA-F & GGA GGA AGG TGG GGA TGA CG & 245 & 60 & [11] \\
\hline 16S rRNA-R & ATG GTG TGA CGG GCG GTG TG & & & \\
\hline erm $\mathrm{A}-\mathrm{F}$ & TAT CTT ATC GTT GAG AAG GGA TT & 139 & 54 & [11] \\
\hline erm A-R & CTA CAC TTG GCT TAG GAT GAA A & & & \\
\hline erm B-F & CTA TCT GAT TGT TGA AGA AGG ATT & 142 & 54 & [11] \\
\hline erm B-R & GTT TAC TCT TGG TTT AGG ATG AAA & & & \\
\hline erm $\mathrm{C}-\mathrm{F}$ & AAT CGT CAA TTC CTG CAT GT & 299 & 54 & [12] \\
\hline erm C-R & TAA TCG TGG AAT ACG GGT TTG & & & \\
\hline msrA-F & TCC AAT CAT TGC ACA AAA TC & 162 & 54 & [13] \\
\hline msrA-R & CAA TTC CCT CTA TTT GGT GGT & & & \\
\hline
\end{tabular}


Table 2. The isolation frequency of S. aureus and S. epidermidis in different clinical specimens.

\begin{tabular}{lcc}
\hline Type of specimen & S. aureus & S. epidermidis \\
\hline Urine & $74(80.4 \%)$ & $62(77.5 \%)$ \\
Blood & $7(7.6 \%)$ & $13(16.25 \%)$ \\
Wound discharge & $6(6.5 \%)$ & - \\
Sputum & $2(2.2 \%)$ & $2(2.2 \%)$ \\
Pleural fluids & $2(2.2 \%)$ & $1(1.1 \%)$ \\
Thermometer & $1(1.1 \%)$ & - \\
Catheter & - & $1(1.1 \%)$ \\
Patient's bed & - & $1(1.1 \%)$ \\
Total & $92(53.3 \%)$ & $80(46.5 \%)$ \\
\hline
\end{tabular}

\section{Antibiotic susceptibility testing}

Resistance to cefoxitin (79.3\%) was the highest in $S$. aureus strains, followed by resistance to oxacillin and erythromycin (ca. $69.6 \%$ and $67.4 \%$, respectively). Linezolid showed potent antibacterial activity against $S$. aureus with a resistance rate of $14.1 \%$. Following linezolid, the rate of resistance to rifampicin in S. aureus strains was $26.1 \%$. Fourteen (15.2\%) S. aureus strains were showed intermediate resistance to clindamycin. Overall, $50 \%, 18.5 \%$, and $31.5 \%$ of the isolates had sensitive, intermediate, and resistant antibiogram profiles against mupirocin, respectively.

$S$. epidermidis strains showed high resistance to cefoxitin (83.8\%). The lowest resistance of S. epidermidis was reported against linezolid (11.2\%). The rate of resistance to oxacillin in $S$. epidermidis strains was also found to be high. 17.5 percent of $S$. epidermidis strains showed an intermediate profile to erythromycin (the highest level), while, 1.2 percent of them had an intermediate profile to tetracycline (the lowest level). The antimicrobial resistance profile of $S$. aureus and $S$. epidermidis is shown in Table 3.

\section{D-test}

The results of D-test showed that 101 (58.7\%) isolates (S. aureus and $S$. epidermidis) were positive for at least one out of four phenotypes (D, $\mathrm{D}^{+}, \mathrm{HD}$, and R) (Fig. 1). As Fig. 2 indicates, distribution of $\mathrm{D}, \mathrm{D}^{+}, \mathrm{HD}$, and $\mathrm{R}$ phenotypes among $S$. aureus strains was detected respectively as $2.17 \%, 10.8 \%, 2.17 \%$, and $35.8 \%$. Prevalence of D, $\mathrm{D}^{+}$, $\mathrm{HD}$, and R phenotypes among S. epidermidis strains was evaluated respectively as $8.75 \%, 8.75 \%, 3.75 \%$, and $46.25 \%$. Overall, 26 S. aureus and S. epidermidis isolates showed inducible resistance phenotypes ( $\mathrm{D}=9$ and $\mathrm{D}^{+}=17$ ), and 75 isolates were found to have constitutive resistance phenotypes $(\mathrm{HD}=5$ and $\mathrm{R}=70)$ (Table 4$)$.

At least one type of erm genes (ermA, ermB, or erm C) was detected in all $S$. aureus isolates and $93.75 \%$ of $S$. epidermidis isolates. The ermB and erm $C$ genes were the most frequent genes among $S$. aureus $(44.6 \%$ and $43.5 \%$, respectively) and $S$. epidermidis $(38.8 \%$ and $43.8 \%$, respectively) strains, while ermA was detected in a few S. aureus (13\%) and S. epidermidis (11.3\%) strains. In addition, erm $B$ and erm $C$ genes were found to have a high frequency in MRSA (57.1\% and 53.1\%, respectively) and methicillin-resistant $S$. epidermidis

Table 3. Antibiogram profile of S. aureus and S. epidermidis.

\begin{tabular}{|c|c|c|c|c|c|c|c|}
\hline \multirow[b]{2}{*}{ Antibiotic } & \multirow{2}{*}{$\begin{array}{c}\text { Concentration } \\
\mu \mathrm{g} / \text { disc }\end{array}$} & \multicolumn{3}{|c|}{ S. aureus } & \multicolumn{3}{|c|}{ S. epidermidis } \\
\hline & & $\begin{array}{c}\text { Resistant } \\
\text { n (\%) }\end{array}$ & $\begin{array}{c}\text { Intermediate } \\
\mathrm{n}(\%)\end{array}$ & $\begin{array}{c}\text { Sensitive } \\
\text { n (\%) }\end{array}$ & $\begin{array}{c}\text { Resistant } \\
\text { n (\%) }\end{array}$ & $\begin{array}{c}\text { Intermediate } \\
\mathrm{n}(\%)\end{array}$ & $\begin{array}{c}\text { Sensitive } \\
\text { n (\%) }\end{array}$ \\
\hline Oxacillin & 1 & $64(69.6)$ & $6(6.5)$ & $22(23.9)$ & $59(73.8)$ & $5(6.2)$ & $16(20)$ \\
\hline Cefoxitin & 30 & $73(79.3)$ & - & $19(20.7)$ & $67(83.8)$ & - & $13(16.2)$ \\
\hline Clindamycin & 2 & $42(45.7)$ & $14(15.2)$ & $36(39.1)$ & $37(46.2)$ & $6(7.5)$ & $37(46.2)$ \\
\hline Erythromycin & 15 & $62(67.4)$ & $20(21.7)$ & $10(10.9)$ & $58(72.5)$ & $14(17.5)$ & $8(10)$ \\
\hline Linezolid & 30 & $13(14.1)$ & - & 79 (85.9) & $9(11.2)$ & - & $71(88.8)$ \\
\hline Fusidic acid & 10 & $34(37)$ & $8(8.7)$ & $50(54.3)$ & $36(45)$ & $4(5)$ & $40(50)$ \\
\hline Tetracyclin & 30 & $58(63)$ & $2(2.2)$ & $32(34.8)$ & $53(66.2)$ & $1(1.2)$ & $26(32.5)$ \\
\hline Gentamicin & 10 & $47(51.1)$ & $4(4.3)$ & $41(44.6)$ & $43(53.8)$ & - & $37(46.2)$ \\
\hline Rifampicin & 5 & $24(26.1)$ & $1(1.1)$ & $67(72.8)$ & $19(23.8)$ & $5(6.2)$ & $56(70)$ \\
\hline Mupirocin & 20 & $29(31.5)$ & $17(18.5)$ & $46(50)$ & $30(37.5)$ & $6(7.5)$ & $44(55)$ \\
\hline
\end{tabular}




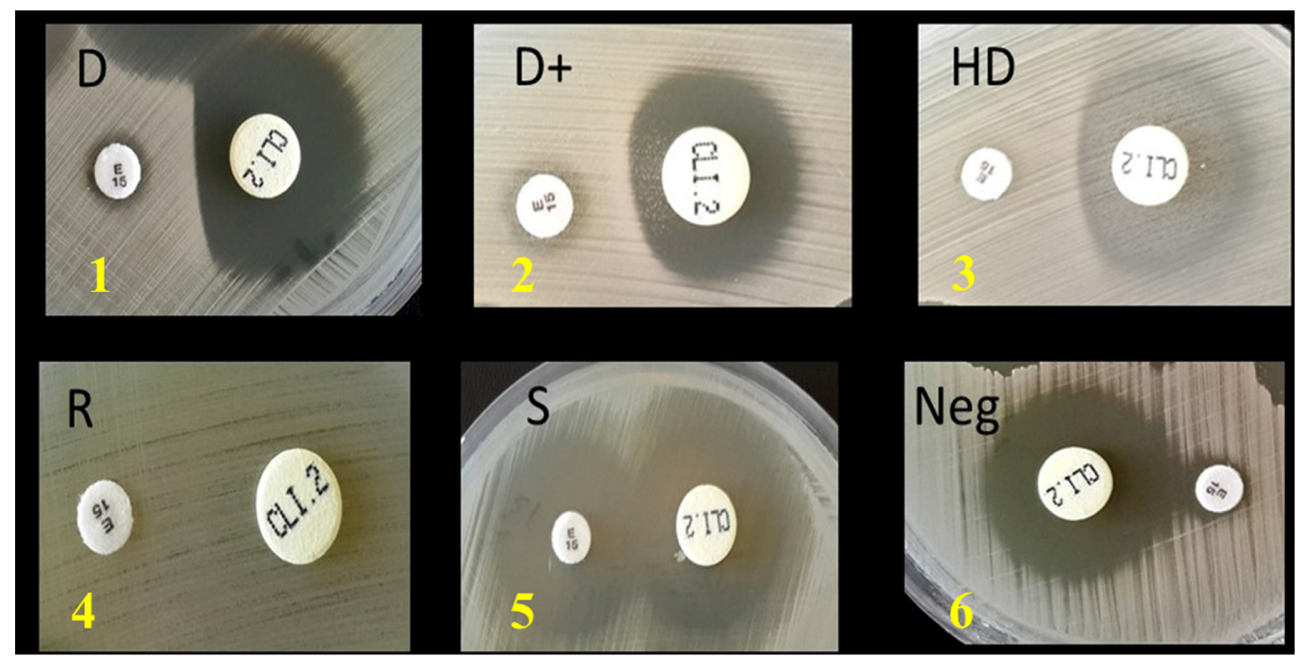

Fig. 1. Different inducible and constitutive phenotypes on Muller Hinton agar plate. CLI: clindamycin, E: erythromycin. 1; In D phenotype, the bacteria is resistant to erythromycin and a D shaped clear zone was seen around the clindamycin disk proximal to the erythromycin disk. 2; In D+ phenotype, in addition to the observed D shaped zone around the clindamycin disk, small colonies were grown at the inhibition zone of the clindamycin disk. 3; In HD (hazy D zone) phenotype, in addition to the observed bacterial growth at the presence of erythromycin, two zones of growth could be observed around the clindamycin disk. 4; In R (Resistant) phenotype, bacteria growth was seen in the presence of erythromycin and clindamycin. 5; In S (Sensitive) phenotype, bacteria growth was not seen in the presence of erythromycin and clindamycin. 6; In Neg (negative) phenotype, the bacteria is resistant to erythromycin while D shaped clear zone was not seen around the clindamycin disk proximal to the erythromycin disk.

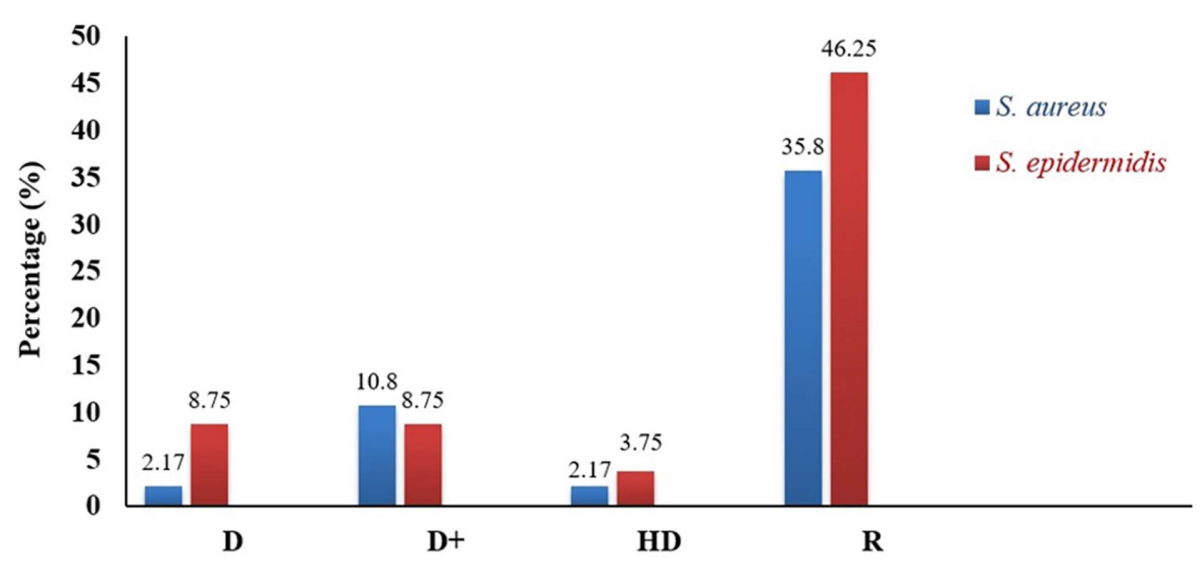

Fig. 2. Frequency of inducible and constitutive phenotypes among S. aureus and S. epidermidis strains. R: resistant, HD: Hazy $\mathrm{D}$ zone. A high percent of $S$. epidermidis and S. aureus isolates showed R phenotype as a constitutive resistance.

(MRSE) (50\% and 53.8\%, respectively) strains (Table 5).

The frequency of erm $A$, ermB, and erm $C$ genes among $S$. aureus and $S$. epidermidis strains which had at least one out of four D-phenotypes was $22.2 \%, 55.6 \%$, and $33.3 \%$, respectively. The corresponding frequencies of these genes in $\mathrm{D}^{+}$-positive strains were $5.9 \%, 41.2 \%$, and 76.5\%, respectively. All HD-positive strains (100\%) concurrently possessed both ermB and erm $C$ genes.
Overall, 20\% of HD-positive strains contained ermA genes. All HD-positive strains (100\%) were also positive for $m s r A$ gene. The frequency of ermA, ermB and ermC genes in R-positive strains was $22.9 \%, 78.6 \%$, and 77.1\%, respectively (Figs. 3 and 4). Among D-negative strains, only one strain was positive for ermA gene. Also, $7 \%$ of these strains were positive for $m s r A$ gene. 
Table 4. Distribution of inducible and constitutive resistance among S. aureus and S. epidermidis strains.

\begin{tabular}{|c|c|c|c|c|c|c|c|}
\hline \multirow{2}{*}{ D-phenotypes } & \multirow{2}{*}{ Resistance phenotype } & \multirow{2}{*}{$\begin{array}{c}\text { ERY } \\
\text { Result }\end{array}$} & \multirow{2}{*}{$\begin{array}{c}\text { CLI } \\
\text { Result }\end{array}$} & \multicolumn{2}{|c|}{$\begin{array}{c}\text { S. aureus } \\
92(53.49 \%)\end{array}$} & \multicolumn{2}{|c|}{$\begin{array}{l}\text { S. epidermidis } \\
80(46.5 \%)\end{array}$} \\
\hline & & & & $\begin{array}{c}\text { MRSA } \\
49(53.3)\end{array}$ & $\begin{array}{c}\text { MSSA } \\
43(46.7)\end{array}$ & $\begin{array}{c}\text { MRSE } \\
52(65) \\
\end{array}$ & $\begin{array}{l}\text { MSSE } \\
28(35) \\
\end{array}$ \\
\hline D zone ${ }^{a}$ & Inducible Resistance & $\mathrm{R}$ & $S$ & $1(8.3)$ & $1(2.9)$ & $3(14.3)$ & $4(12.1)$ \\
\hline $\mathrm{D}^{+}$zone $^{\mathrm{b}}$ & Inducible Resistance & $\mathrm{R}$ & $S$ & $5(41.7)$ & $5(14.3)$ & $5(23.8)$ & $2(6.1)$ \\
\hline HD zone ${ }^{c}$ & Constitutive Resistance & $\mathrm{R}$ & $\mathrm{R}$ & 0 & $2(5.7)$ & 0 & $3(9.1)$ \\
\hline R zone ${ }^{d}$ & Constitutive Resistance & $\mathrm{R}$ & $\mathrm{R}$ & $6(50)$ & $27(77.1)$ & $13(61.9)$ & $24(72.7)$ \\
\hline Total & & & & $12(42.9)$ & $35(67.3)$ & $21(48.8)$ & $33(67.3)$ \\
\hline
\end{tabular}

ERY; Erythromycin, CLl; Clindamycin; a; in D zone phenotype, the isolates are resistant to Erythromycin while sensitive to Clindamycin. b; in $\mathrm{D}^{+}$zone phenotype, the isolates also are resistant to Erythromycin while sensitive to Clindamycin. $c$; in HD zone phenotype, the isolates are resistant to both Erythromycin and Clindamycin. $\mathrm{d}$; in R zone phenotype, the isolates also are resistant to both Erythromycin and Clindamycin.

Table 5. Frequency of ermA, ermB, erm C and msrA genes among S. aureus and S. epidermidis isolates.

\begin{tabular}{lllllll}
\hline & S. aureus & S. epidermidis & MRSA & MSSA & MRSE & MSSE \\
& $\mathrm{N}(\%)$ & $\mathrm{N}(\%)$ & $\mathrm{N}(\%)$ & $\mathrm{N}(\%)$ & $\mathrm{N}(\%)$ & $\mathrm{N}(\%)$ \\
\hline$e r m A$ & $12(13)$ & $9(11.3)$ & $7(14.3)$ & $5(11.6)$ & $7(13.5)$ & $2(7.1)$ \\
$e r m B$ & $41(44.6)$ & $31(38.8)$ & $28(57.1)$ & $13(30.2)$ & $26(50)$ & $5(17.9)$ \\
$e r m C$ & $40(43.5)$ & $35(43.8)$ & $26(53.1)$ & $14(32.6)$ & $28(53.8)$ & $7(25)$ \\
$m s r A$ & $43(46.7)$ & $40(50)$ & $29(59.2)$ & $14(32.6)$ & $31(59.6)$ & $9(32.1)$ \\
\hline
\end{tabular}

MRSA; Methicillin-resistant Staphylococcus aureus, MSSA; Methicillin-Sensitive Staphylococcus aureus, MRSE; Methicillin-Resistant Staphylococcus epidermidis, MSSE; Methicillin-Sensitive Staphylococcus epidermidis.

\section{Genes sequence analysis}

One example of all genes includes $16 \mathrm{~S}$ rRNA, $m s r A$,
ermA, ermB, and erm $C$ were sequenced. Some sequence information of these genes was shown as Table 6.

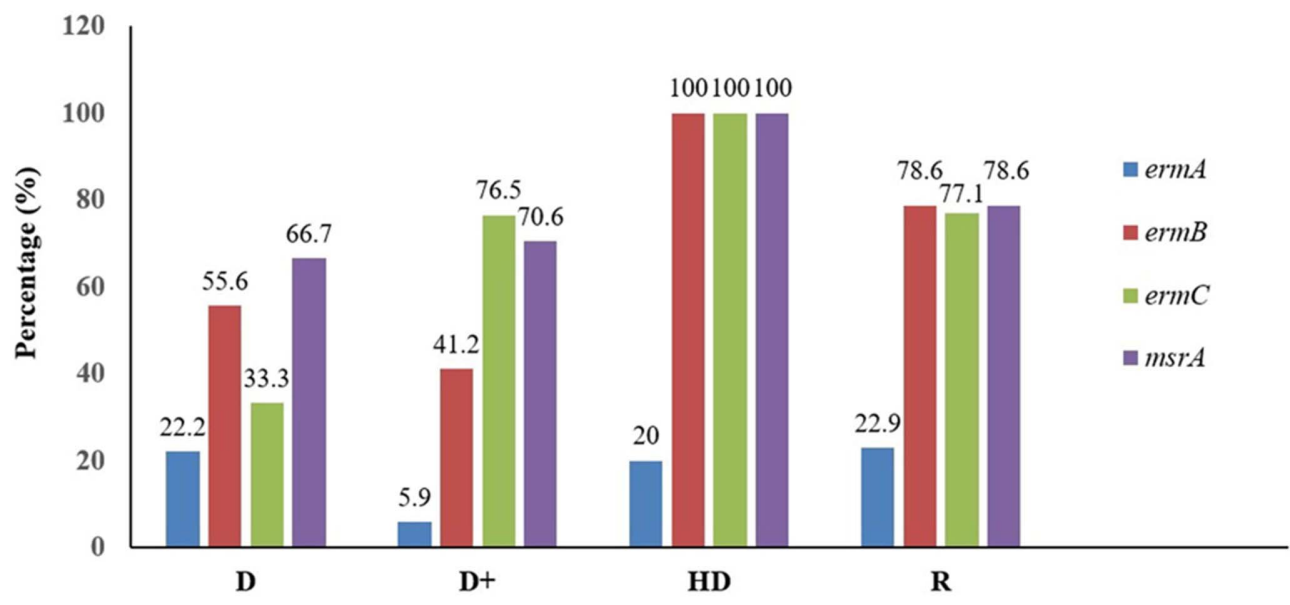

Fig. 3. Distribution of erm and $m s r A$ genes among the isolates of $S$. aureus and $S$. epidermidis with inducible and constitutive resistant. As the figure shows, the frequency of ermB, ermC, and msrA genes in $\mathrm{HD}$ and R phenotypes in S. aureus and S. epidermidis strains showed a high percentage than the prevalence of these genes in $D$ and $D+$ phenotypes. The percentage of the erm $A$ gene is approximately similar in $\mathrm{D}, \mathrm{HD}$, and R phenotypes. 


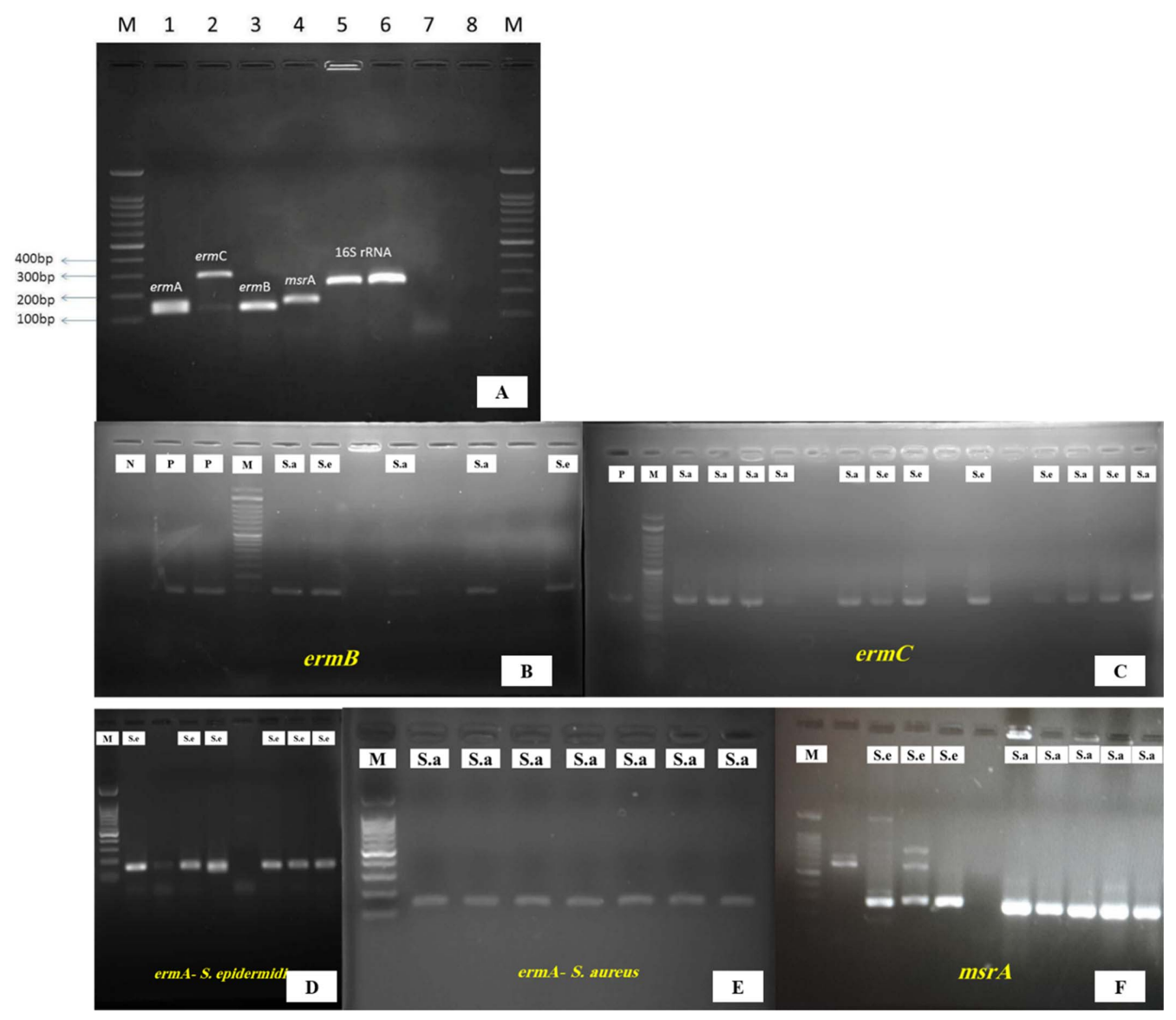

Fig. 4. Agarose gel electrophoresis the PCR product of investigated genes in clinical strains of S. aureus and S. epidermidis. A; Lane 1: ermA positive isolate, Lane 2: ermC positive isolate, Lane 3: ermB positive isolate, Lane 4: $m s r A$ positive isolate, Lane 5: $16 \mathrm{~S}$ rRNA gene of S. aureus, Lane 6: 16S rRNA gene of S. epidermidis, Lane 7: erm negative isolate, Lane 8: PCR negative control. M: Size marker 100 bp. B to E; distinctive erm genes in clinical strains of $S$. aureus and S. epidermidis. F; msrA gene in clinical strains of $S$. aureus and S. epidermidis. S.a; Staphylococcus aureus, S.e; Staphylococcus epidermidis.

Table 6. Genes sequence analysis.

\begin{tabular}{ccccc}
\hline $\begin{array}{c}\text { Gene } \\
\text { name }\end{array}$ & Direction & $\begin{array}{c}\text { Size } \\
\text { (bp) }\end{array}$ & GC\% & $\begin{array}{c}\text { ORF } \\
\text { Number }\end{array}$ \\
\hline ermA & $\mathrm{F}$ & 115 & 34.8 & 2 \\
& $\mathrm{R}$ & 115 & 37.4 & 2 \\
ermB & $\mathrm{F}$ & 118 & 44.1 & 2 \\
& $\mathrm{R}$ & 121 & 44.6 & 1 \\
ermC & $\mathrm{F}$ & 261 & 26.1 & 1 \\
& $\mathrm{R}$ & 278 & 25.2 & 1 \\
msrA & $\mathrm{F}$ & 128 & 36.7 & 2 \\
& $\mathrm{R}$ & 140 & 35.7 & 3 \\
16S rRNA & $\mathrm{F}$ & 222 & 47.3 & 2 \\
& $\mathrm{R}$ & 222 & 47.7 & 2 \\
\hline
\end{tabular}

F; forward, R; reverse, bp; base pair, GC; guanine + cytosine, ORF; Open Reading Frames.

\section{Discussion}

In this study, $S$. aureus was isolated from urine samples at a high rate (80.4\%), while it was not detected in catheter or stretcher samples (0\%). S. epidermidis was also isolated at a high rate from urine (77.5\%), but it was not found in thermometer or wound samples $(0 \%)$. The frequency percentage of urinary $S$. aureus and $S$. epidermidis isolates was significantly different in comparison with other clinical samples. The present findings are not consistent with the results reported by Adhikari et al. from Nepal (2017), as they found that S. aureus was isolated from pus specimens at a high rate (54.4\%), while $S$. aureus was isolated from $7.4 \%$ of urine specimens [11]. Moreover, Khashei et al. in a study from Iran 
(2018) reported that $46.5 \%$ of S. aureus and S. epidermidis strains isolated from the specimens were related to bloodstream infections, respectively. In the study by Khashei et al., the prevalence of $S$. aureus and $S$. epidermidis strains in urine specimens was nearly 15.1\% [12]. Presumably, the high rate of urinary isolates of $S$. aureus and S. epidermidis in our study is related to the high numbers of urinary samples rather than the other samples.

According to the results of disk diffusion test, resistance of $S$. aureus and $S$. epidermidis bacteria to betalactam antibiotics (oxacillin and cefoxitin) was the highest, while linezolid showed the greatest antibacterial activity against $S$. aureus and S. epidermidis. The increased antimicrobial resistance of Staphylococcus strains to beta-lactams may be attributed to the expansion of resistance genes in $S$. aureus and S. epidermidis strains. In this regard, Connor et al. (2015) have reported that $<1 \%$ of S. aureus and $2 \%$ of coagulase-negative Staphylococcus spp. (CoNS) are resistant to linezolid [13]. In another study by Yoo (2020) in Korea, the resistance of $S$. aureus was $14.8 \%$ [14]. The low rate of resistance to linezolid among $S$. aureus and $S$. epidermidis isolates is probably related to the low frequency of mutations in the binding site of ribosome 50s subunit [15]. Also, an RNA methyl transferase gene ( $c f r$ gene) has been recently described in both MRSA and coagulase-negative Staphylococci isolates in the United States and other countries [16].

The results of D-test revealed that R-phenotype was the most common in both $S$. aureus and $S$. epidermidis strains, while HD type had the lowest rate.

Phenotypic conversion from $\mathrm{D}$ to $\mathrm{D}^{+}$and from $\mathrm{HD}$ to $\mathrm{R}$ increased, while conversion from $\mathrm{D}^{+}$to $\mathrm{HD}$ decreased among $S$. aureus and $S$. epidermidis strains; this finding shows that some $S$. aureus and $S$. epidermidis strains do not tend to convert from induced resistance to constitutive resistance (Fig. 2). Our results are in agreement with a report by Majhi et al. [17]. Moreover, Ejikeugwu et al. reported variations in induced and constitutive resistance phenotypes among strains isolated from different locations [18]. In our study, Staphylococcus strains (S. aureus and S. epidermidis) with $\mathrm{R}$ phenotypes constituted the majority of strains. This may be a source of concern in health centers as these strains acquire and express individual resistance genes involving clindamycin and erythromycin.
Based on the PCR results, erm (ermB and erm C) and $m s r A$ genes were detected in $100 \%$ of $S$. aureus and $S$. epidermidis strains with HD phenotypes and constitutive resistance. Nearly $77-78 \%$ of strains with $\mathrm{R}$ phenotypes exhibited erm genes (ermB and ermC) and $m s r A$ gene (Fig. 3). The number of $S$. aureus and $S$. epidermidis strains with $\mathrm{D}$ and $\mathrm{D}^{+}$phenotypes (inducible resistance), as well as erm (ermB and erm C) and $m s r A$ genes, was lower than the number of strains with $\mathrm{HD}$ and $\mathrm{R}$ phenotypes. In all inducible and constitutive phenotypes (D, $\mathrm{D}^{+}, \mathrm{HD}$ and $\mathrm{R}$ ), ermA gene was detected in only a few strains of $S$. aureus and $S$. epidermidis (<25\%). Also, ermB gene was the most frequent gene among MRSA strains, followed by erm $C$ gene.

In MRSE strains, erm $C$ gene was dominant, followed by erm $B$ gene. Conversely, erm $A$ gene had the lowest frequency among MRSA and MRSE strains. The $m s r A$ gene showed a frequency rate of $>65 \%$ among all Dphenotypes of $S$. aureus and S. epidermidis strains.

Additionally, in a study by Jarajireh et al., the frequency of erm $C$, ermB, and ermA genes among $S$. aureus strains was reported to be $82.4 \%, 58.8 \%$, and $29.4 \%$, respectively [19]. In a study by Paz Pereira from Brazil (2016), ermA and $e r m C$ genes were found individually in $9.1 \%$ and $38.6 \%$ of isolates with $\mathrm{MLS}_{\mathrm{B}}$ resistance phenotypes of Staphylococcus strains, respectively [20]. In another study by Talebi et al. from Iran (2019), the frequency of erm $C$, ermB, and ermA genes in $S$. aureus strains was $10 \%, 7.5 \%$, and $5 \%$, respectively. In the study by Talebi et $a l$., the frequency of erm $C$ gene strains was the highest among resistant strains of $S$. aureus; this finding is in disagreement with our results [10]. In previous studies, the frequency distribution of erm $C$, ermB, and ermA genes in relation to D-phenotypes has not been investigated; therefore, it is recommended to study the distribution of D-phenotype-positive strains of Staphylococcus in different parts of the world. In conclusion, based on the findings, phenotypic conversion increased from $\mathrm{D}$ to $\mathrm{D}^{+}$and from $\mathrm{HD}$ to $\mathrm{R}$, whereas conversion from $\mathrm{D}^{+}$to HD decreased in $S$. aureus and $S$. epidermidis strains. It seems that, some $S$. aureus and $S$. epidermidis strains did not tend to convert from induced resistance to constitutive resistance. The ermA gene showed the lowest prevalence $(<25 \%)$ among all inducible and constitutive phenotypes of $S$. aureus and $S$. epidermidis $\left(\mathrm{D}, \mathrm{D}^{+}, \mathrm{HD}\right.$, and R). Conversely, ermB and erm $C$ genes were found to 
be the most frequent genes among MRSA and MRSE strains, respectively. Spread and distribution of inducible resistance genes among $S$. aureus and $S$. epidermidis strains can lead to an increase in constitutive resistance to erythromycin, clindamycin, and other similar antibiotics; therefore, treatment of infections can be challenging due to the presence of these resistant strains. We suggest both molecular and phenotypic methods as routine procedures can be used to detect inducible resistance in S. aureus and S. epidermidis strains in clinical microbiology laboratories.

\section{Acknowledgments}

The authors gratefully acknowledge the facility support provided by Urmia University of Medical Sciences.

\section{Conflict of Interest}

The authors have no financial conflicts of interest to declare.

\section{References}

1. Miller LS, Fowler Jr VG, Shukla SK, Rose WE, Proctor RA. 2020. Development of a vaccine against Staphylococcus aureus invasive infections: Evidence based on human immunity, genetics and bacterial evasion mechanisms. FEMS Microbiol. Rev. 44: 123-153.

2. Goudarzi M, Kobayashi N, Dadashi M, Pantůček R, Nasiri MJ, Fazeli M, et al. 2020. Prevalence, genetic diversity, and temporary shifts of inducible clindamycin resistance Staphylococcus aureus clones in Tehran, Iran: a molecular-epidemiological analysis from 2013 to 2018. Front. Microbiol. 11: 663.

3. Yao W, Xu G, Li D, Bai B, Wang H, Cheng H, et al. 2019. Staphylococcus aureus with an erm-mediated constitutive macrolide-lincosamidestreptogramin B resistance phenotype has reduced susceptibility to the new ketolide, solithromycin. BMC Infect. Dis. 19: 175.

4. Liu X, Deng S, Huang J, Huang Y, Zhang Y, Yan Q, et al. 2017. Dissemination of macrolides, fusidic acid and mupirocin resistance among Staphylococcus aureus clinical isolates. Oncotarget 8: 58086-58097.

5. Sabaté Brescó $M$, Harris LG, Thompson K, Stanic B, Morgenstern M, O'Mahony L, et al. 2017. Pathogenic mechanisms and host interactions in Staphylococcus epidermidis device-related infection. Front. Microbiol. 8: 1401.

6. Juda M, Chudzik-Rzad B, Malm A. 2016. The prevalence of genotypes that determine resistance to macrolides, lincosamides, and streptogramins B compared with spiramycin susceptibility among erythromycin-resistant Staphylococcus epidermidis. Mem. Inst. Oswaldo Cruz. 111: 155-160.

7. Wayne P. 2017. Performance Standards for Antimicrobial Susceptibility Testing: Twenty-Seventh Informational Supplement
M100-S27. Wayne, PA: CLSI.

8. Tille P. 2017. Bailey \& Scott's diagnostic microbiology-E-Book, pp. 252-261. Ed. Elsevier Health Sciences.

9. Mendem SK, Gangadhara TA, Shivannavar CT, Gaddad SM. 2016. Antibiotic resistance patterns of Staphylococcus aureus: A multi center study from India. Microb. Pathog. 98: 167-170.

10. Talebi G, Hashemia A, Goudarzi $H$, Shariati A, Bostanghadiri $N$, Sharahi JY, et al. 2019. Survey of ermA, ermB, ermC and mecA genes among Staphylococcus aureus isolates isolated from patients admitted to hospitals in Tehran, Iran by PCR and sequencing. Biomed. Res. 30: 259-263.

11. Adhikari R, Shrestha S, Barakoti A, Amatya R. 2017. Inducible clindamycin and methicillin resistant Staphylococcus aureus in a tertiary care hospital, Kathmandu, Nepal. BMC Infect. Dis. 17: 483.

12. Khashei R, Malekzadegan Y, Ebrahim-Saraie HS, Razavi Z. 2018. Phenotypic and genotypic characterization of macrolide, lincosamide and streptogramin B resistance among clinical isolates of staphylococci in southwest of Iran. BMC Res. Notes 11: 711.

13. O'Connor C, Powell J, Finnegan C, O'gorman A, Barrett S, Hopkins $\mathrm{K}$, et al. 2015. Incidence, management and outcomes of the first cfr-mediated linezolid-resistant Staphylococcus epidermidis outbreak in a tertiary referral centre in the Republic of Ireland. J. Hosp. Infect. 90: 316-321.

14. Yoo IY, Kang O-K, Shim HJ, Huh HJ, Lee NY. 2020. Linezolid resistance in methicillin-resistant Staphylococcus aureus in Korea: High rate of false resistance to linezolid by the VITEK 2 system. Ann. Lab. Med. 40: 57-62.

15. Ruiz-Ripa L, Feßler AT, Hanke D, Eichhorn I, Azcona-Gutiérrez JM, Alonso CA, et al. 2021. Mechanisms of linezolid resistance among clinical Staphylococcus spp. in Spain: Spread of methicillin-and linezolid-resistant S. epidermidis ST2. Microb. Drug Res. 27: 145-153.

16. Musumeci R, Calaresu E, Gerosa J, Oggioni D, Bramati S, Morelli P, et al. 2016. Resistance to linezolid in Staphylococcus spp. clinical isolates associated with ribosomal binding site modifications: novel mutation in domain V of 235 rRNA. New Microbiol. 39: 269-273.

17. Majhi S, Dash M, Mohapatra D, Mohapatra A, Chayani N. 2016. Detection of inducible and constitutive clindamycin resistance among Staphylococcus aureus isolates in a tertiary care hospital, Eastern India. Avicenna J. Med. 6: 75-80.

18. Ejikeugwu C, Nwezeagu F, Edeh C, Eze P. 2018. Detection of constitutive and inducible-clindamycin-resistance in clinical isolates of Staphylococcus aureus from a Federal Teaching Hospital in Abakaliki, Nigeria. J. Bacteriol. Infect. Dis. 2: 31-34.

19. Jarajreh Da, Aqel A, Alzoubi H, Al-Zereini W. 2017. Prevalence of inducible clindamycin resistance in methicillin-resistant Staphylococcus aureus: the first study in Jordan. J. Infect. Dev. Ctries. 11: 350-354.

20. da Paz Pereira JN, Rabelo MA, da Costa Lima JL, Neto AMB, de Souza Lopes AC, Maciel MAV. 2016. Phenotypic and molecular characterization of resistance to macrolides, lincosamides and type B streptogramin of clinical isolates of Staphylococcus spp. of a university hospital in Recife, Pernambuco, Brazil. Braz. J. Infect. Dis. 20: 276-281. 